\author{
Revista Venezolana de Gerencia (RVG) \\ Año 8. № 22, 2003, 307-322 \\ Universidad del Zulia (LUZ) • ISSN 1315-9984
}

\title{
Lo ético de la ética empresarial
}

\section{Crespo, Miguel Francisco}

\section{Resumen}

La proliferación de discursos sobre la ética empresarial, que en los últimos años se ha presentado en el mundo de los negocios, nos lleva a preguntarnos por las razones que posibilitan dicho fenómeno. Hallar una respuesta a esta pregunta, hace necesario descubrir los verdaderos propósitos que mueven los esfuerzos que en la actualidad se realizan por lograr una ética empresarial. Con esta finalidad, se analiza, en primer lugar, lo escrito por Adela Cortina, quien es la promotora y defensora más influyente en el mundo de habla hispana del discurso sobre la ética de los negocios; en segundo lugar, se indaga el devenir histórico de los discursos en torno a la ética empresarial. El despliegue de ambas actividades nos lleva a concluir que la "euforia" en torno a la ética de los negocios, responde a que, gracias a dicho fenómeno, el modelo empresarial capitalista puede lograr dos propósitos, el pri mero de los cuales es de especial trascendencia porque le permite al sistema permanecer de manera incuestionable. Los mencionados propósitos son: Legitimar socialmente el sistema organizacional e incrementar sustancialmente su rentabilidad.

Palabras clave: Ética, estructura organizacional, conciencia, identidad, responsabilidad.

\section{The Ethics of Business Ethics}

\section{Abstract}

The proliferation of discourse on management ethics, which over the last few years has been present in the business world, leads one to question the reasons behind this phenomenon. In order to answer this question it is first necessary discover the true purpose behind these efforts which are presently being made to establish business ethics. With this purpose in mind, the writings of Adela Cortina, an influential promoter and defender of these ideas in the Spanish speaking world in relation to business ethics, are analyzed, and then the historical development of the discourse of business ethics is questioned. The display of both activities leads one to conclude the "euphoria" around the ethics of business is related to the capitalistic business model which hopes to achieve two objectives. The first objective is of special transcendence, since it permits the system to undoubtedly continue. The purposes are: socially legitimize the organizational system, and to substantially increase revenue.

Key words: Ethics, organizational structure, conscience, identity, responsibility.

Recibido: 02-07-26 . Aceptado: 03-02-05

* Profesor de la Universidad Autónoma de La Laguna, México. Magister en Administración y Educación. Cursante del Doctorado en Sistemología Interpretativa en la Universidad de los Andes, Venezuela. E-mail: migcrespo@hotmail.com 


\section{Introducción}

El fin del siglo $X X$ fue testigo, entre otras cosas, del surgimiento de una serie de discursos en torno a la ética empresarial y a la responsabilidad de las organizaciones. Estos discursos han sido acompañados por el nacimiento de distintos organismos "independientes", a nivel mundial, cuyo propósito central es el de fomentar en las empresas un comportamiento ético y responsable. Así, organizaciones como Ética para Los Negocios y Organizaciones (ETNOR); la Fundación Probidad; la Fundación Empresa y Sociedad; el Instituto Latinoamericano de Ética Civil Empresarial; el Instituto Latinoamericano de Liderazgo, Desarrollo Humano y Organización; entre muchas otras, inundan hoy en día los mercados (incluyendo el ciberespacio), ofreciendo a las organizaciones públicas y privadas una serie de servicios, sobre todo de capacitación y consultoría, con la finalidad de "re-moralizar"1 el desempeño empresarial y organizacional. Estas "empresas consultoras" apoyan la promoción de sus servicios sobre la base de distintas publicaciones (libros, revistas, artículos en Internet, etcétera), que intentan persuadir al empresariado de la necesidad que tienen de responsabilizarse de sus acciones y de los efectos que sus empresas ocasionan.

Por su parte, las organizaciones empresariales (cámaras y confederaciones por ejemplo), así como los gobiernos de muchos países, se han unido a esta ola de la ética empresarial, promoviéndola no sólo a través de cursos y charlas, sino además, creando premios y otros incentivos para aquellas empresas que se destacan debido a su comportamiento ético y al cumplimiento de su responsabilidad social. Así mismo, aquellas organizaciones que sobresalen en este ámbito, centran sus esfuerzos de comunicación (interna y externa) en resaltar dichas características ellas son presentadas como ventaja competitiva importante, lo que a la vez motiva a otras empresas que, atraídas por el seductor slogan de "la ética es rentable", deseen implantar programas de esta naturaleza.

Ante esta "euforia" por la ética empresarial, cabe preguntarse: ¿Nos encontramos ante una "moda" más del discurso empresarial o por el contrario, hay un cambio profundo en las estructuras de este mundo neoliberal que apunta hacia el replanteamiento de las actuales formas económicas y sociales?

Para poder dar respuesta a lo anterior, es necesario primero, conocer a fondo el discurso actual en torno a la ética empresarial. ¿Qué aporta de "nuevo" ese discurso (si es que lo hace)? ¿De dónde surge y a quién va dirigido? ¿Con qué finalidad se lanza dicho discurso? ¿Cómo está construido? ¿Qué lo fundamenta? En lo que sigue, se intenta dar respuesta a dichas interrogantes. Para ello, se discute lo escrito por Adela Cortina, de quien se puede decir, al menos en el mundo del habla hispana, que es la máxima representante y promotora de la ética empresarial. 


\section{2. ¿Qué es la ética empresarial?}

La ética, según Cortina, "es un tipo de saber de los que pretende orientar la acción humana en un sentido racional; es decir, pretende que obremos racionat mente". Dicho saber ético tiene fundamentalmente dos modos: el primero, es la forja de carácter con el que se busca aprender a tomar decisiones prudentes; el segundo es la toma de decisiones moralmente justas, que la autora relaciona con "el respeto de los derechos humanos desde una moral crítica" (Cortina, 1994:19-25).

Ante la pérdida de legitimidad de la religión católica que era fuente de la ética durante la Edad Media, el mundo occidental vio surgir en la Modernidad la ética cívica. En su obra "Ética de la Empresa (1994)", la autora nos narra cómo, a partir de los eventos que posibilitaron el pluralismo (la convivencia pacífica entre ciudadanos de diferentes credos y por tanto, códigos morales), se hace necesario el establecimiento de unos mínimos morales que garanticen la buena convivencia entre los ciudadanos, pero que, además, emerjan de dicha convivencia. Ello motiva el nacimiento de la ética cívica. La ética empresarial es parte de ella, pero no cualquier parte. Para Cortina, no es posible una ética empresarial sin una ética cívica; pero lo mismo se puede decir en el sentido contrario, no es posible una ética cívica sin una ética empresarial pues, se- gún piensa esta autora, sin organizaciones morales toda la sociedad se desmoralizaría.

Pero el contexto de la ética cívica no es el único para la ética empresarial, la empresa capitalista requiere del marco de la "ética de la economía capitalista" de la cual, nos dice Cortina (1994), la empresa sería su "espíritu". Para ella, el capitalismo ha demostrado ser la mejor forma económica, ya que posibilita tanto la libertad de los individuos como la democracia que, bajo un modelo comunitario, hace posible encontrar esos mínimos morales requeridos por la ética cívica.

La ética empresarial es pues, "el descubrimiento y la aplicación de los valores y normas compartidos por una sociedad pluralista -valores que componen la ética cívica- al ámbito particular de la empresa, lo cual requiere entenderla según un modelo comunitario, pero siempre empapado de postconvencionalismo" 2 (Cortina, 1994:89).

Según esa definición, quien desee aplicar o desarrollar algún programa de ética empresarial en su organización, debe primero identificar los valores que en la sociedad existen. Una vez identificados, debe "aplicarlos" en su empresa, invitando a los demás miembros de la organización a asumirlos para que se conviertan en los valores de la empresa, los que serán válidos en tanto se encuentren fundamentados en los principios universales y en los derechos humanos. aquel en el que no se considera justo lo que se adecua a las normas de una sociedad concreta, sino a principios universales, a derechos humanos y valores superiores. 
Sin embargo, suponer que es necesario el deseo o la intención de alguien para aplicar ética empresarial es una idea errónea según los promotores de la ética de los negocios. Para Cortina, como para el resto de los promotores de la ética empresarial, es falsa la idea de que las empresas se conviertan en éticas por decisión de alguien. Las empresas son necesariamente éticas, lo que pasa es que su comportamiento puede ser moralmente ejemplar o puede no serlo, pero nunca una empresa puede ser a-moral. El papel de "Iíder" empresarial, no es por tanto el de decidir si su empresa será ética o no (es decir, si tendrá un ethos -carácter-o no), en todo caso, lo que pueden, y deben hacer los líderes empresariales, es orientar ese comportamiento para que sea moral.

La discusión sobre si la empresa tiene un ethos o no, es un punto crítico en el discurso de Cortina pues, de no poder mostrar la existencia de un ethos de la empresa, dicho discurso se caería, convirtiéndose en todo caso en uno sobre la "ética del empresario"; mismo que seguramente quedaría subsumido dentro de la teoría ética y la filosofía moral tradicionales.

En "Rentabilidad de la ética para la empresa (1997)", la autora intenta resolver esa situación a través de una analogía. Partiendo de la explicación "estructuralista" de la moral de las personas, muestra cómo se forma la "estructura moral" de las empresas. Una persona, nos dice la autora desde la "tradición estructuralista", al enfrentarse a su medio para garantizar su viabilidad, se ve obligada a adoptar la siguiente conducta:

1. No percibe el medio como simple estímulo, al modo del animal, sino que lo intelige como una realidad a la que debe responder.

2. Debido a su hiperformalización, no responde mecánicamente, con lo cual se abre aquí un momento de indeterminación, de libertad en un primer y básico sentido.

3. La respuesta no es automática, sino que el organismo humano diseña distintas posibilidades de respuesta, distintos cursos de acción a través de los cuales podría adaptar el medio a sus necesidades y deseos. El organismo humano funciona, pues, de forma autopoiética.

4. Obligado a elegir entre los cursos de acción, debe tomar decisiones y necesariamente elige la que considera mejor, lo cual significa que debe juzgar su elección, dar razón de ella. En todo este proceso es esencial el papel de la conciencia, que hace presentes los valores y las metas desde los que se debe elegir. Sin conciencia de esas metas y valores, hipoteca su libertad y actúa como ser heterónomo, no como un ser autónomo.

5. El organismo humano se apropia de la posibilidad elegida y va generando un carácter -un ethos-que no le viene dado por nacimiento, sino del que se "adueña" a lo largo de su vida al ir apropiándose las posibilidades que considera mejores. Ese carácter va configurando la identidad compulsiva de la persona, "una definición de sí mismo, en parte implícita, que un agente humano debe poder elaborar en el curso de su conversión en adulto y seguir redefiniendo a lo lago de su vida". Esta identidad tiene al menos tres dimensiones: La moral, desde la 
que el individuo distingue entre lo que es importante para él y lo que no lo es; la personal, por la que reconoce su particular modo de ser humano, su originalidad; y la social, ya que para identificarse a sí mismo, precisa del reconocimiento ajeno.

6. Por último, un organismo capaz de emprender distintos cursos de acción y obligado a justificar su opción por at guno de ellos está también estructuralmente obligado a responder de sus elecciones, a asumir la responsabilidad por sus decisiones (Cortina, 1997:23-24).

Cortina concluye que, dado el anterior proceso, "las personas son sujetos morales porque gozan de un nivel de conciencia, se ven obligadas a justificar sus decisiones, van forjándose una identidad que les distingue de las demás personas y han de hacerse responsables de sus acciones. Conciencia, justificación de las decisiones, identidad y responsabilidad son dimensiones que no pueden faltar en entidades que se pretendan morales" (Cortina, 1997:24).

Como se ilustra en el diagrama 1 , el factor que da unidad a la estructura moral de las personas, según la tradición estructuralista a la que dice apelar Cortina, es la conciencia. Así, dado que el individuo tiene conciencia, debe justificar sus decisiones (las puede identificar como suyas y por tanto debe dar razón de ellas), lo que va constituyendo en él una identidad, que a la vez le permite ir asumiendo su responsabilidad.

Antes de continuar, cabe aquí mencionar que no todos los filósofos morales estarían de acuerdo con el proceso de formación del carácter que se acaba de citar, en especial, por la concepción individualista de la que parte, en donde el papel de los demás, queda reducido al de "reconocer" al sujeto para que este pueda identificarse, es decir, tener una identidad. Para autores como MacIntyre ${ }^{3}$ por ejemplo, entender la dimensión moral de la identidad como la distinción entre lo

\section{Diagrama 1 \\ Estructura moral de las personas}

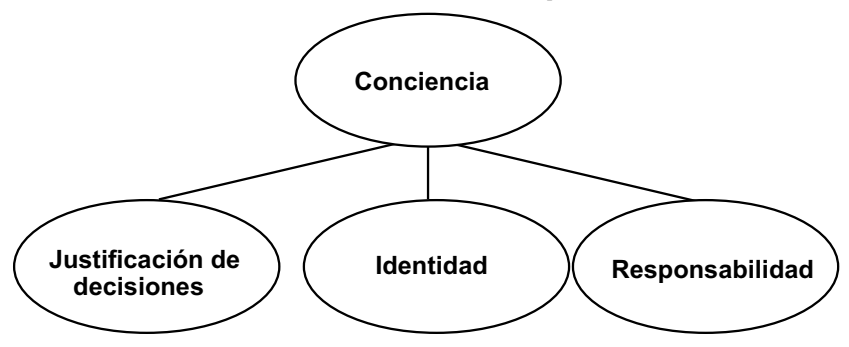

3 Me parece muy importante mencionar este desacuerdo de origen con MacIntyre, pues gran parte del trabajo de Adela Cortina está apoyado supuestamente en el trabajo de ese filósofo contemporáneo. 
que es importante para el individuo y lo que no lo es, es simplemente inaceptable. Pues, según Maclntyre, el hombre no puede entender lo que es bueno para él, si no ha participado de las relaciones sociales para el bien común ${ }^{4}$. Otro gran punto de des-acuerdo entre Maclntyre y Cortina, estaría en la supuesta necesidad de dar razones de las acciones. Maclntyre respondería que, por ejemplo, si se ayuda a un extraño que se encuentra en una urgente necesidad, "ofrecer o solicitar una justificación es en sí mismo, una muestra de defecto en las virtudes [morales]" (Maclntyre 1999:158).

Pero supongamos, no obstante lo anterior, que la postura estructuralista ofrece una buena explicación sobre la formación de la estructura moral de las personas. ¿Cómo es entonces la analogía propuesta por Cortina?

Las organizaciones, dice Cortina, "tienen una estructura que les permite to- mar decisiones colectivas, no reductibles ni a las de los individuos ni tampoco a las de agregados de individuos. Lo cual significa, en primer lugar, que debe tomar conciencia de qué valores y metas deben orientar sus decisiones, porque son los que le ayudarán a ir conformando una identidad, un carácter, propio de la organización. Y significa, en segundo lugar, que la organización, como tal, debe hacerse responsable de sus decisiones y de las consecuencias previsibles que de ellas se sigan" (Cortina, 1997:25).

Haciendo el mismo ejercicio de esquematización que hacíamos respecto a la estructura moral de las personas, la "estructura moral" de las empresas luciría como se ilustra en el diagrama 2; lo que brinda unidad a la "estructura moral" de las empresas es, valga la redundancia, su estructura para la toma de decisiones. En efecto, dado que las organizaciones tienen una estructura para tomar decisiones

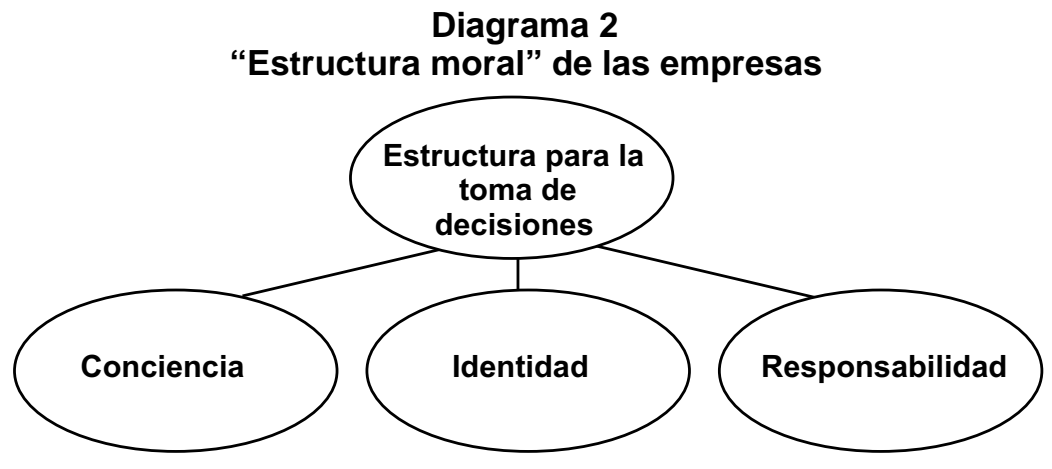

$4 \quad$ Un buen ejemplo de lo que constituye la perspectiva de Maclntyre en torno a la formación del ethos puede ser encontrado es su texto Dependent Rational Animals (1999). En dicho libro, Maclntyre muestra como una de las grandes fallas de la filosofía moral, ha sido la de considerar a los seres humanos como independientes y plenos en su capacidad del uso de la razón. 
colectivas, tienen que tomar una conciencia sobre los valores y metas que deben orientar esas decisiones, ello le permitirá ir formándose una identidad. Además, tiene que hacerse responsable de dichas decisiones y de sus consecuencias.

Comparando ambos diagramas, nos comienza a parecer algo "extraña" la analogía formulada por Cortina. Recordemos que, según el modelo que ella misma sugiere como base de su analogía, en la estructura moral de las personas la conciencia es aquello que da unidad al agente moral. Esto es, al menos teóricamente, que el sujeto no puede ni justificar razones, ni tener identidad, ni responsabilizarse de sus actos, si no tiene a priori una conciencia. Sin embargo, en su modelo para la empresa, no puede utilizar ese mismo factor como generador de unidad. Una razón para ello es que, de hacerlo, inevitablemente tendría que aceptar que la famosa "conciencia colectiva", no es más que la suma de las conciencias individuales; señalar lo contrario, sería afirmar que un colectivo puede darse cuenta de algo que sus miembros no pueden en lo particular notar.

Ante la imposibilidad de emplear la conciencia como unidad para su esquema, recurre a utilizar la estructura para la toma de decisiones colectivas. Sin embargo, no es exactamente en lugar de la conciencia, ya que esta, según su modelo, más bien es "descendida" de nivel, quedando reducida al lugar que ocupaba la justificación de las decisiones en el sujeto. Ello hace que la conciencia tenga tan sólo una importancia secundaria en su esquema de la "estructura moral empresarial", lo que sin duda contrasta con el papel fundamental que tiene en el caso de las personas. ¿Qué tan válida es una analogía como la propuesta por Cortina, sobre todo si lo que se pretende es construir una teoría ética a partir de ella?

Revisando cómo lucen los rasgos de la "estructura moral" en las empresas. Rasgos que, para Cortina (1997), no pueden faltar en entidades que se pretendan morales. El primero, es la ya citada "estructura para la toma de decisiones" que, según la autora, toda organización tiene. Cuestionemos a Cortina. ¿De dónde surge la estructura organizacional? ¿Se tratará de algo que "brota" por generación espontánea o será, el resultado final de una serie de decisiones que una persona, o un grupo "selecto" de ellas han realizado?

Quien esté un poco familiarizado con la teoría organizacional responderá sin mucha dificultad, que la estructura organizacional es producto del diseño de lo que Fuenmayor ha denominado como "sistema formal de actividades" (Fuenmayor, 2000). Esto es, que la empresa no tiene una estructura sino que se le "da" una. En ella, quienes tienen el poder para hacerlo (el dueño o la "alta gerencia"), plasman una serie de comportamientos que les son deseables.

Se refutará a lo anterior, mencionando que, una cosa es lo que se pone en el papel, y otra muy diferente lo que ocurre en la realidad. Se dirá que si bien es cierto que "alguien" establece una estructura, también es cierto que en la práctica, la gente va modificando ese diseño dada la convivencia cotidiana. No obstante, es importante recordar que si bien el diseño de la estructura formal de una organización responde a un ideal que difícilmente se cumple, también es cierto que en dicho diseño se hace explícita, en mayor o me- 
nor medida, toda una serie de mecanismos (premios y castigos) que pretenden garantizar que la estructura original sea respetada.

Suponiendo sin conceder, que las estructuras de las empresas cobran "vida propia" y que quienes en ellas laboran modifican tanto sus códigos de conducta individuales como los que el diseño estructural planea, dando como resultado un comportamiento "particular de la organización”, lo cual, de algún modo validaría la analogía propuesta por Cortina, entonces debemos preguntarnos ¿Cuál sería, según esta autora, la problemática moral "de fondo" a resolver?

Teniendo las empresas una "estructura moral", el problema estaría en torno a los contenidos de dicha estructura. Esta cuestión, nos dice la autora, hace inevitable para la empresa la necesidad de "debatir con los afectados por ella, porque el quehacer empresarial tiene repercusiones sociales y, por tanto, ha de verse también socialmente legitimado" (Cortina, 1997:25). Obviamente dicho debate tendría que ser en torno a los valores que la sociedad exigiría de sus empresas, lo que supone que la empresa ha generado los mecanismos apropiados para posibilitar tal discusión. Nuevamente habría que preguntar si la mera organización basta para decidir establecer dichos mecanismos o bien, si es "alguien" (que solo puede ser el empresario o alguno de los altos gerentes) que, partiendo de su propia estructura moral, decide que su empresa debe establecer dichos mecanismos.

El segundo rasgo abordado por la autora es el de la responsabilidad. Para ella, "existe un procedimiento aceptado, más o menos explícito, a través del cual se toman decisiones, de suerte que el responsable de las decisiones tomadas no es cada uno de los miembros de la organización, sino la organización en su conjunto" (Cortina, 1997:25).

Parecerá redundante pero, nuevamente preguntamos a Cortina. ¿De dónde salen esos procedimientos? ¿No hay entonces acaso un responsable de ellos, de generarlos y de hacerlos cumplir? Pero, aún suponiendo que estos emergen de la nada. ¿Por qué aceptarlos? ¿Acaso no es ya la aceptación de un procedimiento, una decisión moral individual? Y nuevamente, si las decisiones y las responsabilidades son colectivas. ¿Por qué se castiga a quien se equivoca dentro de una organización, por ejemplo, con el despido? ¿Nos es acaso que, finalmente hay un responsable de una mala decisión y que es por eso que tiene que asumir las consecuencias de ello? Aún aceptando que hay decisiones mal tomadas que afectan a la organización en su totalidad, ¿Qué se gana diluyendo la responsabilidad?

Un tercer rasgo análogo de las empresas con respecto a las personas, nos dice la autora, es la conciencia. Siguiendo a su discípulo Goodpaster (1996), Cortina nos dice que la conciencia corporativa, es "un proceso institucional para $<$ hacer balance > de la prosecución de un objetivo económico, proceso a lo largo del cual es importante que se escuche la voz de los <<stakeholders>>" (Cortina, 1997:26). Así, para que la empresa pueda "adquirir" esta conciencia, estos autores (Goodpaster y Cortina), nos proponen una serie de pasos que van desde la articulación de una filosofía corporativa, hasta la reflexión y revisión de los valores 
adoptados, pasando por acciones de educación para lo cual escuchar es fundamental.

En este punto, la analogía vuelve a tornarse bastante débil pues pareciera que, de no cumplir con dicho proceso o con alguno similar (que nuevamente tiene que ser promovido por el dueño o algún miembro de la alta gerencia) la mencionada conciencia simplemente no aparece $y$, sin conciencia, no hay moral ${ }^{5}$. Ahora bien, ¿El desarrollo de la conciencia humana depende de la aplicación de un proceso explícitamente lanzado para ello? La respuesta es obviamente no. En otras palabras, mientras para los humanos la conciencia es algo que les es dado en tanto que se-es-ser-humano, las empresas necesitan seguir diversos mecanismos para desarrollar ese artificio que algunos osan llamar conciencia de la organización.

Finalmente, la analogía termina evocando la noción de cultura organizacional para, a partir de ella, determinar una identidad para la empresa. Según Cortina, las organizaciones "cuentan con una cultura, expresiva de los valores, creencias e ideales compartidos, sean los de lograr el máximo beneficio por cualquier medio o los de mantener la viabilidad y competitividad con medios bien ponderados" (Cortina 1997:27). Debemos recordar aquí, que el punto que Cortina intenta defender es el de que las empresas son necesariamente morales y que su estructura moral le permite tomar decisiones colectivas no reductibles ni a las de los individuos ni tampoco a las de grupos de individuos. Dado lo anterior, podría uno pensar en el siguiente ejemplo. Suponga usted una empresa cuyos "valores, creencias e ideales compartidos", están enfocados al logro del máximo beneficio por cualquier medio; entre esos medios, estaría incluida la sobre-explotación de la mano de obra como uno de los principales costos que hay que abatir al máximo en cualquier organización ${ }^{6}$. Las preguntas que aparecen son, entre otras: ¿Cómo pueden "compartir valores", en dicho ejemplo, el patrón explotador y sus trabajadores sobre-explotados? ¿Cuáles son esos valores que comparten? ¿Por qué en empresas donde los obreros son sobre-explotados, existen problemas laborales? ¿Por qué aparecieron los sindicatos? ¿No será entonces que el problema ético no es de "la empresa" sino, como históricamente lo ha sido, del empresario?

\section{3. ¿Por qué promover una "ética empresarial" y no una "ética del empresario"?}

Ante lo hasta aquí expuesto, habrá quién desee seguir la lógica aquella que dice que "el fin justifica los medios", y que si hay un discurso, por muy inconsistente

5 Al menos para los individuos pues, como ya hemos visto, para Cortina la conciencia en las empresas no es algo necesario para la estructura moral, sino algo solamente accesorio.

6 Pregúntese por ejemplo, qué es la reingeniería sino, un mecanismo para "repartir" el mismo trabajo entre menos gentes, con una notable disminución de costos, vía nómina, en el corto plazo. 
que este sea, que logre en los empresarios un cambio de comportamiento tal que se resuelvan los grandes problemas de desigualdad en el mundo, lejos de criticarlo hay que apoyarlo y fomentarlo. Ante esas posibles voces, habría que descubrir primero, si ese que piensan es el objetivo de los discursos en torno a la ética empresarial o, si por el contrario, lo que pretenden es dar mayores herramientas para que la lógica de la acumulación de la riqueza se perpetúe. Por otra parte, si lo que se pretende es el cambio de actitud de los empresarios, ¿por qué no se promueve una ética del empresario?

Antes de responder a dichas interrogantes es necesario retomar dos preguntas que anteriormente nos hacíamos y que, en este punto parece importante responder. La preguntas eran en torno a lo que aporta de nuevo el discurso sobre la ética empresarial lo cual, por tanto, nos obliga a preguntarnos por su devenir histórico. Para dar respuesta a estos puntos, es necesario revisar brevemente cómo han surgido los discursos en materia de ética empresarial en la historia y cuáles han sido sus propósitos.

Contrariamente a lo que se dice, la empresa no es un fenómeno universal perteneciente a todas las culturas de todos los tiempos. Las empresas son producto de lo que hoy llamamos Modernidad. No obstante, y siguiendo a Weber $(1994)^{7}$, el "espíritu del capitalismo" ha existido desde siempre en la humanidad, si por él entendemos la actitud que lleva a algunos seres humanos a acumular más riquezas de las necesarias para vivir bien. Antes de la Modernidad, sin embargo, dicha actitud era de unos cuantos cuyo comportamiento era moralmente reprochable. Lo que hace especial al "espíritu" singularmente moderno del capitalismo, es que aparece como fenómeno de masas.

Esta "masificación" del espíritu del capitalismo fue posible gracias, en gran parte, a cierta interpretación de las sagradas escrituras, realizada por algunos grupos calvinistas, en la que la acumulación de riquezas y "la profesión" eran vistas como un medio para lograr la salvación. Sin embargo, como descubre Weber en su investigación, no debe pensarse que esta interpretación estaba hecha pensando en fomentar la economía capitalista. Lo que realmente sucedió, según lo indagado por Weber, es que algunos empresarios notaron por ejemplo que, por contraste con las obreras tradicionales que tenían un mal desempeño laboral, "las jóvenes con sólida formación religiosa, en especial pertenecientes a la secta pietista, se manifestaban de muy distinto modo..." (Weber, 1994:38).

Los empresarios en ese tiempo buscaban la manera de vencer el "tradicionalismo", primer enemigo que tenía que derrotar el espíritu del capitalismo y que refiere a la actitud de los trabajadores que los llevaba a laborar exclusivamente hasta ganar lo indispensable para vivir, echando a perder los planes de los empresarios que, por la vía del pago a destajo, intentaban incrementar la productivi- 
dad y con ello sus ganancias. Por tanto, el descubrimiento del efecto que el discurso pietista tenía a favor de una nueva actitud frente al trabajo por parte de quienes profesaban dicha forma religiosa hace, entre muchos otros ejemplos similares, que los empresarios se apropien de la ética protestante que, no sólo les es útil para lograr que los trabajadores produzcan más, sino que además, les da una justificación moral, "legitimando" su actividad, otrora vista con desprecio por la sociedad.

No obstante, cuando los empresarios asumieron el discurso de la ética protestante, este era ya un discurso cuya legitimidad estaba condenada a morir. En efecto, la Modernidad estaba precisamente impulsada por un afán de autonomía moral, en la que los individuos reclamaban la posibilidad de tomar decisiones morales sin la intervención de agentes externos a él. Hay que recordar que, a lo largo de la Edad Media, la religión católica gracias a su función hermenéutica en relación con la verdad revelada, era la responsable de decidir lo que era moralmente aceptable y lo que no. Hay que recordar también, que es durante ese proceso lento y paulatino de emancipación que llamamos Modernidad, que las religiones en Occidente pierden gradualmente su legitimidad como fuentes de verdad.

Así las cosas, el discurso de la ética protestante, no era uno, del cual el "espíritu capitalista" se pudiera "agarrar" per- petuamente. Era necesario encontrar uno nuevo que permitiera legitimar socialmente su actividad. Esta nueva fuente de discurso, aparece en una Modernidad más avanzada, la de la "llustración Radical", y aparece de la mano de la "ciencia económica". Adam Smith, padre de la economía, es también un filósofo moral que, al mismo tiempo que trata de explicar el comportamiento económico, desarrolla una propuesta filosófica moral en la que la relación del amigo-comercial se vuelve el paradigma. El altruismo y la idea de la "contribución patriótica sacrificada para el crecimiento económico del Estado-Nación" son, a partir de entonces, dos grandes virtudes propias de todo empresario ético. Virtudes que encuentran un fundamento, en la razón y la ciencia ${ }^{8}$.

Este discurso "científico-económico", permanecería así con algunas modificaciones, hasta la segunda mitad del siglo XX. No obstante, dejaría de ser suficiente para contrarrestar las críticas contra el sistema capitalista. Los años sesenta y setenta, de ese siglo, fueron caracterizados por una fuerte ola de movimientos marxistas en todo el mundo, que cuestionaban fuertemente la legitimidad de la empresa capitalista. Según estas críticas, no era posible que un sujeto fuera moralmente ejemplar si era dueño de una empresa, ya que esta, fuese la que fuese, era una forma inmoral de explotación de las mayorías. Esto, entre otros fenómenos contemporáneos como la consolida- 
ción de la administración como profesión, es lo que hace posible y necesaria la aparición de una ética de la empresa, con el propósito de legitimar socialmente la empresa como actividad.

Peter F. Drucker, uno de los pioneros de la ética empresarial justifica la aparición de ésta, diciendo que "la explicación más usual y obvia [para la aparición de la ética empresarial] no es la acertada. La aparición del reclamo de responsabilidad social no se explica por un sentimiento de hostilidad a la empresa. Por el contrario, el éxito del sistema empresario es el factor que conduce a expectativas nuevas y en muchos casos exageradas. La exigencia de responsabilidad es en medida considerable el precio del éxito" (Drucker, 1973:217).

Drucker no deja muy en claro, sin embargo, la respuesta sobre qué justifica que se deje de hablar de la ética del empresario, para ahora hablar de la ética empresarial. Cuando mucho, permite inferir que son las legislaciones fiscales las que de alguna manera posibilitan dar una "personalidad jurídica" a la empresa, y con ello aparecen las exigencias fiscales a las empresas más allá de los empresarios. No obstante, esa explicación sigue pareciendo insuficiente, si lo que se intenta conocer es qué nos permite pensar en la empresa como un agente moral.

Este vacío, es lo que el discurso de Cortina y los nuevos "filósofos" promotores de la ética empresarial intentan cubrir con sus aportaciones. Es ello lo que su trabajo trae de nuevo a la idea de ética de los negocios. Sin embargo, como hemos visto, pareciera aún muy débil la argumentación hasta ahora presentada como para aceptar la idea de que las empresas tienen una ética propia. Pero, si no es fácil asignar a la empresa un ethos, ¿Por qué la insistencia? ¿Qué gana el modelo capitalista-empresarial si se logra la aceptación de que es la empresa y no el empresario la que debe comportarse éticamente?

Hay dos tipos de ganancias que el sistema capitalista-empresarial obtendría de darse dicha aceptación (y con esto respondo a los dos cuestionamientos plantedos al inicio de esta sección, a saber, el propósito del discurso contemporáneo sobre la ética empresarial y, por tanto, el por qué no se promovía una ética para el empresario). Las ganancias del primer tipo son las relacionadas con la legitimación social de la actividad empresarial. Las ganancias del segundo tipo son aquellas referidas a la rentabilidad de las empresas. Revisemos a continuación cómo el discurso contemporáneo sobre la ética empresarial intenta alcanzar esas ganancias.

\section{Los propósitos de la ética empresarial}

Legitimar socialmente a la empresa, como decíamos, es el primer y más fundamental tipo de ganancia que se busca al consolidar la idea de que las empresas son agentes morales y que, por lo tanto, hay que exigir de ellas y no de sus dueños un comportamiento ético. De hecho, esa ha sido la intención de todo discurso empresarial a través del tiempo. Hoy en día, son distintos los medios que los promotores de la ética empresarial utilizan para lograr este fin, pero quizás el principal consista en "apropiarse" y "trastocar" el trabajo filosófico serio con el fin, no sólo de "fundamentar" sus opiniones, 
sino peor aún, de hacer aparecer su discurso justificador y legitimador de la empresa capitalista, como altamente aceptado por la comunidad filosófica y sus más destacados representantes 9 . Un ejemplo de lo anterior es el uso que le da Cortina (1994) al trabajo de Macintyre en torno a la cara interna y externa de los bienes generados por una "práctica"10.

En su libro After Virtue (tras la virtud), el filósofo Alasdair Maclntyre define una práctica como "Toda forma coherente y compleja de actividad humana cooperativa, socialmente establecida, mediante la cual se realizan bienes internos a esa forma de actividad, en la medida en que se intentan alcanzar esos patrones de excelencia que son apropiados para, y que parcialmente definen a, esa forma de activi dad; con el resultado de que los poderes humanos para alcanzar la excelencia y las concepciones de los fines y bienes envuet tos son sistemáticamente mejorados" (MacIntyre, 1985:187, traducción propia).

Los bienes producidos en las prácticas manifiestan dos caras: Una cara interna, que es la apreciación del mejor estado del bien por parte de aquellos que están inmersos en la práctica y que para apreciar dicho estado y para poder alcanzarlo, necesariamente tienen que desarrollar las virtudes propias de la práctica. $Y$ una cara externa, que puede ser apreciada por aquellos que no están relacionados en la práctica y que, como consecuencia al "practicante" le puede traer fama, dinero o poder.

Dado lo anterior, una empresa no puede ser considerada una práctica puesto que, entre otras cosas, su propósito fundamental está en función de alcanzar la cara externa del bien, en otras palabras, lo que ahí se fabrica es necesariamente con el propósito de ser vendido. En una práctica, un taller artesanal del medioevo, por ejemplo, lo que se producía se hacía pensando en alcanzar la excelencia del bien no importando si este iba a ser vendido o no. Fabricar bienes para no ser vendidos bajo el modelo capitalista-empresarial, es simplemente una aberración.

Cortina nos presenta otra versión de lo anterior. Los bienes internos son aquellos que sólo puede lograr cierta actividad. "La actividad docente, por ejemplo se desarrolla para intentar transmitir los saberes que los hombres con esfuerzo

9 Basta asomarse brevemente en la literatura generada por los promotores de la ética empresarial, para encontrar entremezclados sin ningún pudor, a filósofos como Aristóteles, Sócrates, Spinoza, Kant, Adam Smith, Hume, Apel, Habermas, Foucault, Taylor, Maclntyre, entre muchos otros; en una "sopa ecléctica" en la que todo es bienvenido, mientras pueda ser presentado en apoyo al "espíritu capitalista".

10 Es difícil suponer el desconocimiento del trabajo de Maclntyre por parte de Cortina pues, por ejemplo, lo cita cuando dice que "Maclntyre en su libro Tras la virtud, en el que señala que el manager es uno de los personajes centrales de la sociedad postcapitalista, si es que queremos representarnos dicha sociedad como una pieza teatral para entenderla mejor" (Cortina, 1994:82). Y es precisamente en ese libro, en el que el filósofo desarrolla su tesis sobre los bienes de una práctica. 
hemos ido adquiriendo, de modo que tanto quienes los transmiten como quienes los reciben puedan llevar una vida lo más plena posible. Por su parte, la actividad política cobra su legitimidad social de intentar satisfacer, a través del uso del poder legítimamente adquirido, los intereses universables, y no los de determinados sectores; mientras que la actividad sanitaria persigue los bienes que le son propios cuando busca el bien de los pacientes, eliminando la enfermedad y el dolor en la medida posible" (Cortina, 1994:23).

¿Y de la actividad empresarial, cuál será su bien interno? Cortina responde: "La meta de la actividad empresarial es la satisfacción de necesidades humanas a través de la puesta en marcha de un capital", del que es parte esencial el capital humano -los recursos humanos-, es decir, las capacidades de cuantos cooperan en la empresa. Por tanto, el bien interno de la actividad empresarial consiste en lograr satisfacer esas necesidades y de forma inseparable, en desarrollar al maximo las capacidades de sus colaboradores, metas ambas que no podrá alcanzar si no es promocionando valores de libertad, igualdad y solidaridad desde el modo específico en que la empresa puede y debe hacerlo" (Cortina, 1994:43). Resaltado nuestro.

Al menos dos fallas se manifiestan en esta idea de que, la satisfacción de necesidades humanas, es el bien interno de la actividad empresarial. La primera es que esa satisfacción sólo puede ser apreciada por los usuarios de los bienes y servicios que proporciona la organización, es decir, por agentes externos a la "práctica" organizacional, lo cual le quita precisa- mente el carácter de bien interno según la definición de Maclntyre. La segunda tiene que ver con lo indefinido del bien interno que se propone para la actividad empresarial. Según Cortina (1994), el bien interno del servicio de salud es lograr la sanidad de las personas; el de la docencia es la transmisión de saberes, etcétera. La pregunta es, ¿La salubridad y la educación, no son necesidades humanas? ¿No hay acaso empresas que se dedican a la educación o a la salud, por ejemplo? ¿Es que acaso ellas tienen un bien interno "doble"? ¿Cuál es entonces el bien interno de la actividad empresarial?

Parece que es necesario recordar la definición de empresa. Una empresa es, según el diccionario de la Real Academia de la lengua española una "Entidad integrada por el capital y el trabajo, como factores de la producción, y dedicada a actividades industriales, mercantiles o de prestación de servicios con fines lucrativos". Es decir que, por definición, la empresa cobra sentido inevitablemente a partir de la búsqueda de dinero, que es un bien externo. Por tanto, no hay tal bien interno que, como dice la noción de Maclntyre, defina como práctica a la actividad empresarial. Cortina no ignora la mencionada definición de empresa, de lo contrario no hablaría de "puestas en marcha de capital" que, aunque suavizado así, sigue evocando a la aspiración lucrativa que da sentido a la actividad empresarial.

La deformación hecha al discurso de Maclntyre es tan sólo un ejemplo, entre muchos, del intento por manipular la opinión para favorecer una visión en la que la empresa aparece como "la forma" de satisfacer necesidades humanas, de 
tal manera que, la acumulación de riquezas sea vista como la consecuencia lógica y justificada que llega por el riesgo asumido y el sacrificio por los demás, por parte de los siempre buenos y siempre bien intencionados empresarios.

$Y$ este punto nos lleva a pensar en el otro tipo de ganancias que la ética empresarial busca, las de la rentabilidad. Aunque ya autores como Drucker (1973) advertían las posibilidades que una "imagen ética y responsable" era buena oportunidad para incrementar las ganancias, hoy en día, los "filósofos-vendedores" de la ética empresarial, no tienen ningún empacho en anunciar que "la ética es rentable, entre otras cosas, porque actuar correctamente ahorra gastar en derecho, es decir, en leyes, juicios y sanciones" (Cortina, 1994:50).

Entre las ventajas que las organizaciones de consultoría ofrecen a quienes deciden hacer de su empresa una empresa ética, se encuentran el mejoramiento del desempeño financiero, reducción de costos operativos y mejoramiento de la imagen de la marca y la reputación. Todos los "casos de éxito" que son presentados por dichas empresas consultoras a través de sus distintos medios de propaganda, buscan resaltar este aspecto. Eso lo hacen, obviamente, con el propósito de "endulzar" los oídos del empresario, cliente potencial de estas empresas de consultoría, el mismo que no "consumiría" ética empresarial si ésta no fuera un gran negocio.

\section{Conclusión}

Con lo hasta aquí expuesto, podemos concluir que la moda aparente de la ética empresarial se hace posible porque esta busca que el sistema capitalista-empresarial logre dos grandes metas: legitimarse y, por ende, perpetuarse; e incrementar la rentabilidad. Estos dos objetivos, sin embargo, se verían entorpecidos si lo que se estuviera pregonando fuera una ética del empresario, y la razón para ello radica principalmente en que esta última no impide la posibilidad de cuestionar el sistema. Si la actividad empresarial deja de ser vista como un acto humano para entonces aparecer como algo que trasciende lo humano, elimina toda posibilidad de ser juzgado moralmente, debido a que simple y sencillamente ya no es algo que dependa de nosotros. La decisión de poner un negocio, sea este legal o ilegal, no podría nunca ser cuestionada porque ya esa decisión misma es una manifestación de los "actos de la empresa"; porque puestas así las cosas, pareciera que la empresa pre-existe al ser humano.

Aceptar que las empresas y las organizaciones son agentes morales es aceptar su existencia "natural" y "universal". Si bien es cierto que la forma dominante contemporánea de actividad humana cooperativa es la organización, y cada vez más abrumadoramente la organización específicamente empresarial, eso no quiere decir que haya sido ni que deba ser la única forma. No lo debe ser, porque posibilita la desigualdad y la injusticia humana. La posibilita porque acepta sin ningún pudor el hecho de que quienes menos tienen al iniciar la relación, se subordinen al que más tiene, en un esquema que, además, persigue incesantemente que la diferencia entre unos y otros, cada vez sea más grande. En la 
presente época en la que pregonamos la igualdad de todos los seres humanos, no puede permanecer sin cuestionar, nuestra actual manera de trabajar en colectivo. En ese sentido, si tuviera que existir una "ética empresarial", tendría que ser una que revisara cómo es que ese artificio humano que llamamos empresa es fuente de esas desigualdades y de esas injusticias y por qué, en consecuencia, tenemos que buscar otras formas de cooperar como humanos, necesariamente distintas a aquellas que están definidas por el fin de lucrar.

\section{Bibliografía Citada}

Cortina, Adela (1994), Ética de la empresa": Claves para una nueva cultura empresarial. Editorial Trota. Madrid.

Cortina, Adela; Castiñeira, Angel; Losano, Joseph M.; Domingo, Agustín; Lozano, J. Félix; García-Marzá, Domingo; Cunill, J. La empresa. Editorial Argentania-Visor. Madrid.
Drucker, Peter (1973), La gerencia: Tareas, responsabilidades y prácticas. $\mathrm{Li}-$ brería "El Ateneo" Editorial. Buenos Aires.

Fuenmayor, Ramsés (2001), Interpretando organizaciones... Una teoría sistémico-interpretativa de organizaciones. Universidad de los Andes. Consejo de Publicaciones. Consejos de Estudio de Postgrado. Mérida, Venezuela.

Maclntyre, Alasdair (1985), "After virtue: a study in moral theory". Gerald Duckworth \& Co. Ltd. London.

Maclntyre, Alasdair (1999), "Dependent rational animals: Why human being need the virtues". Open Court. Chicago and La Salle Illinois.

Weber, Max (1994), "La ética protestante y el espíritu del capitalismo”. Ediciones Coyoacán. México. 